\title{
Direitos humanos e diálogo com o século XXI na Carta Magna da Umbanda
}

\author{
Human rights and dialogue with the 21st century in the Magna Carta of Umbanda \\ Derechos humanos y diálogo con el siglo XXI en la Carta Magna de la Umbanda
}

ArturCesar Isaia

\section{Resumo}

Este texto aborda um documento atual, representativo do posicionamento de alguns líderes da Umbanda. A questão central do documento são os direitos humanos, procurando articular a Umbanda com pautas atuais e com as organizações micro e macrossociais no país e no mundo. Nesse sentido, posiciona-se, entre outras, frente a questões que envolvem a cidadania, o gênero, a ecologia e a política reprodutiva.

Palavras-chave: Direitos humanos. Religiões mediúnicas. Umbanda.

\section{Introdução}

A Carta Magna da Umbanda ${ }^{1}$ é um documento que veio a público no ano de 2013, firmado por elementos significativos da religião no Brasil, e, desde então, está sendo debatido dentro e fora do âmbito religioso. Procura tornar claro o posicionamento da Umbanda frente a questões complexas e atuais, capazes de dividir não apenas os integrantes do campo religioso, mas também a opinião pública.

Questões que vão da preservação do meio ambiente aos preconceitos raciais e de gênero, passando pela política contraceptiva, pela eutanásia e pelos direitos dos animais, são tratadas neste documento. Além disso, problemas eminentemente voltados para a vivência de uma democracia plura-

\footnotetext{
Doutor em História Social pela Universidade de São Paulo. Professor titular da Universidade Federal de Santa Catarina e professor colaborador do Programa de Pós-Graduação em História na mesma instituição. E-mail: arturci@uol.com.br
}

Recebido em 23.07.2018 - Aprovado em 15.09.2018 http://dx.doi.org/10.5335/hdtv.19n.1.8405 
lista são enfocados na Carta Magna, como os limites da ação do estado sobre os indivíduos e a participação na política nacional em todos os níveis.

Devido à importância dos temas, cujo posicionamento os representantes da Umbanda tentam explicitar neste documento, penso que o seu estudo e a sua divulgação mereçam uma atenção especial por parte de todos os que investigam as religiões no Brasil e seu relacionamento com as lutas políticas e a afirmação dos direitos humanos. O documento é indiciário de uma postura não apenas intrarreligiosa, mas também claramente voltada para a macropolítica da atualidade. O documento se insere em uma conjuntura na qual constantemente as religiões são interpeladas pelas perplexidades de homens e mulheres, que vivenciam um momento caracterizado pela "aceleração do tempo" (KOSELLECK, 2006), em que certezas milenares transformam-se em polêmicas e dúvidas existenciais.

\section{Dirigentes umbandistas e a luta pela representatividade}

A Carta Magna da Umbanda foi uma iniciativa de um grupo de dirigentes umbandistas, sob a liderança de Ortiz Belo de Souza, sacerdote umbandista de São Paulo, cidade em que nasceu em 1969 e desenvolve sua atuação religiosa no templo Portais da Umbanda. Os religiosos que firmaram este documento desenvolveram, como todos os sacerdotes umbandistas, um investimento pessoal em alçar-se como líderes da religião, porque a Umbanda, ao contrário de outras religiões em que existem um livro sagrado fundante e estruturante do seu universo doutrinário, bem como autoridades institucionalizadas que por elas falam, não possui nem uma coisa nem outra. Na Umbanda, os templos estão mais sujeitos à autoridade do dirigente, que é investido de uma chefia que envolve questões rituais, comportamentais e, logicamente, doutrinárias. Assim, para quem se aventura a estudar a Umbanda e as demais religiões afro-brasileiras, as generalizações não são bem-vindas (PRANDI, 2005), e é necessário conhecer o cotidiano dos diferentes terreiros, em que se vai encontrar o real "fazer-se" da religião. Apesar dessa atomização da autoridade na Umbanda, historicamente encontram-se alguns dirigentes e intelectuais ligados à religião, levando adiante um esforço tanto representativo quanto unificador de forças. Nesse sentido, apontam os três primeiros congressos da Umbanda ocorridos em 1941, 1961 e 1973, na cidade do Rio de Janeiro. Esses congressos foram momentos nos quais se firmou o projeto de alguns dirigentes, tentando falar pela Umbanda e representá-la nos âmbitos religioso e civil. Embora historicamente a Umbanda não tenha desenvolvido uma camada sacerdotal rigidamente monopolizadora da gestão do sagrado, processo descrito por Bourdieu (2001) como inerente ao aprofundamento da divisão do trabalho religioso, é inegável o aparecimento de líderes e intelectuais umbandistas, imbuídos "de um projeto normatizador, querendo impor-se às práticas multifacetadas que caracterizaram e caracterizam a religião" (ISAIA, 2012, p. 1). Ortiz Belo de Souza é um desses dirigentes. $\mathrm{Na}$ falta de um consenso sobre quem exerce a autoridade e quais as atribuições dos líde- 
res na Umbanda, as disputas intestinas são muito comuns. Em relação à própria Carta Magna, grupos diferentes, representados por lideranças diferentes, tentaram ter a última palavra sobre o documento, provocando discussões no interior do campo umbandista. Marme Rosa, líder umbandista, que nasceu em Santa Maria, RS, e, atualmente, exerce funções religiosas em Balneário Camboriú, SC, relata a divisão de forças ocorrida por ocasião do lançamento do texto da Carta Magna da Umbanda em São Paulo, em 2013 (ROSA, 2016). Na ocasião, outra liderança umbandista do estado de São Paulo, apoiada por algumas federações do ABC Paulista, tentou reverter a autoridade de Ortiz Belo de Souza na condução e na representação do documento. O mesmo Marme Rosa ratifica o projeto unificador, capaz de chegar a uma interlocução baseada em uma autoridade representativa e em uma explicitação político-doutrinária, inerente ao documento proposto por Ortiz Belo de Souza:

[...] temos muita gente que vai apoiar para registrar ou no Ministério da Cultura [o texto da Carta Magna da Umbanda]. Vamos registrar. Isso aqui é umbanda [...]. E já aprovada e reconhecida por toda a Umbanda do país inteiro (ROSA, 2016, não paginado).

\section{A Carta Magna: lideranças umbandistas frente às perplexidades de um mundo em transformação}

A Carta Magna da Umbanda integra um projeto mais amplo defendido por Ortiz Belo de Souza, no sentido de explicitar um posicionamento para a religião e possibilitar um diálogo efetivo com a sociedade civil e com as esferas de poder. Assim, Pai Ortiz, como é conhecido entre os umbandistas, fundou o Movimento Político Umbandista (MPU). Este movimento surgiu em 2012 visando a possibilitar a discussão e a organização política entre os umbandistas. O movimento apareceu integrando a estratégia de organizar politicamente os umbandistas e levar ao parlamento candidatos afinados com "Sacerdotes de Umbanda e Candomblé" (MOVIMENTO..., 2014). Falando pelo movimento, Ortiz Belo de Souza apresentou Ronei Costa Martins como candidato afinado com a Umbanda nas eleições para deputado estadual de São Paulo em 2014 (MOVIMENTO..., 2014). Não conseguindo eleger-se deputado estadual, Ronei Costa Martins é atualmente vereador em Limeira, SP, tendo já ocupado o cargo de Presidente da Câmara Municipal desta cidade, entre 2013 e 2014, integrando a bancada do Partido dos Trabalhadores (CÂMARA..., 2013).

Não era nova a tentativa dos umbandistas de organizarem-se em torno de lideranças políticas que representassem seus interesses nos parlamentos estaduais. Brown (1985) apresentou a participação política dos umbandistas, nos anos 1950 e 1960, como um "grupo de interesse político", unido em torno de lideranças. Birman (1985) defendeu o papel de mediação política das Federações de Umbanda. Já Concone e Negrão (1985) estudaram alguns processos de clientelismo político na Umbanda no estado de São Paulo durante a década de 1970. No Rio Grande do Sul, Isaia (2009), Horta (2016) e Moraes (2017) analisaram a trajetória política de 
Moab Caldas como articulador dos interesses umbandistas e primeiro representante da Umbanda no parlamento estadual, no final dos anos 1950 e na década de 1960.

Como era de se esperar em um documento proposto por uma religião afro-brasileira, a Carta Magna dedica interesse especial no que concerne aos preconceitos, ocupando destaque a questão do chamado "preconceito racial":

A Umbanda não aceita o preconceito étnico e racial. O preconceito racial é antes de tudo, uma demonstração de atraso espiritual e desconhecimento das Leis Divinas. Aquele que diminui ou persegue o irmão pela cor da pele ou por qualquer outra característica étnica, viola a regra de ouro presente nas mais diversas tradições espirituais e religiosas (CARTA..., 2012, não paginado).

Nem poderia ser diferente, quando a Umbanda, desde a segunda metade do século $X X$, vem reconfigurando sua identidade na direção do passado africano, ultrapassando uma representação refratária dessa herança, típica dos primeiros tempos da religião (ISAIA, 2010). A Carta Magna da Umbanda articula-se com o fortalecimento étnico, identitário e religioso de valorização do passado afrodescendente, típico das primeiras décadas do século XXI (SILVA, 2011).

Procurando explicitar o posicionamento da Umbanda sobre temas próximos à representatividade política da religião, aos direitos humanos, à política ambiental, entre outros, a ideia de uma Carta Magna emerge das discussões do MPU. A vinculação do movimento à Declaração Universal dos Direitos Humanos da Organização das Nações Unidas (ONU) é destacada por Ortiz Belo de Souza na apresentação do documento:
Uma religião que preza a igualdade, respeitando a Declaração Universal dos Direitos Humanos através da Carta da ONU - Organização das Nações Unidas deve ter este documento máximo, a missão de dignificar seus milhares de seguidores, deixando o legado para a posteridade (SOUZA, 2017, não paginado).

A proposta era oficializar o documento no Congresso Nacional de Umbanda, que se realizou na Câmara Municipal de São Paulo, em agosto de 2013. Durante esse congresso houve, no entanto, a divisão de forças entre o MPU e as lideranças do ABC Paulista, relatada anteriormente por Rosa (2016). Esta divisão parece ter sido a causa para que o MPU apresentasse a Carta Magna da Umbanda como uma iniciativa do grupo liderado por Ortiz Belo da Souza, sem a participação das referidas lideranças, conforme aparece na redação atual do documento (SOUZA, 2017).

O interessante na proposta da Carta Magna é que o documento não é apresentado como uma codificação da Umbanda. Ao contrário de iniciativas anteriores, nas quais a pretensão normativa aparecia explicitamente, o documento apresenta-se como um projeto inconcluso. O texto de apresentação, da autoria de Ortiz Belo de Souza, propõe que a Carta Magna seja revisada, completada, repensada, segundo as demandas da sociedade e as transformações da religião. Diferentemente de outros documentos, principalmente os produzidos em meados do século passado, interessados em normatizar liturgica e doutrinariamente a religião (ISAIA, 2012), a Carta Magna apresentou-se apenas como "base orientadora para respostas aos estudantes de teologia, sociologia, 
filosofia e aos seguidores da religião" (DOCUMENTO..., 2012). Nesse sentido, um diferencial do documento, comparativamente a outros anteriormente publicados por dirigentes e intelectuais da Umbanda, é a pretensão extranacional da prática umbandista. Embora se reconheça que a Umbanda é uma religião brasileira, o documento deixa clara a sua inserção em um mundo de fronteiras cada vez menos rígidas:

Realçando que a Umbanda está em vários países, levando a paz e a elevação de uma religião que defende os direitos pela igualdade, respeitando a pluralidade de cada nação. As bases da Carta Magna de Umbanda são o registro dos princípios seguidos por religiosos de Umbanda pelo mundo (CARTA..., 2012, não paginado).

\section{Inclusão, família e direito à vida na Carta Magna da Umbanda}

Outro diferencial da Carta Magna, em comparação a outros documentos exarados de representantes umbandistas, diz respeito ao seu caráter inclusivo no tocante ao reconhecimento das uniões homoafetivas, às diversidades de gênero e, consequentemente, à pluralidade de modelos familiares. Nesse sentido, o documento explicita que, na Umbanda:

[...] todo ser humano é visto como irmão espiritual, sendo aceita qualquer orientação sexual e identidade de gênero. Assim, a religião entende e acolhe Espíritos, e não o gênero ou a sexualidade. Discriminação e preconceito não são ensinados pelos nossos Guias Espirituais, posto que a Umbanda acolhe a todos. Desta forma, é fundamental respeitarmos a condição de cada indivíduo: heterossexualidade, homossexualidade, bissexualidade, transexualidade e intersexualidade são questões de foro íntimo e pessoal (CARTA..., 2012, não paginado).
Dessa forma, o documento reconhece o casamento religioso como um sacramento, contudo, prevê a possibilidade de matrimônio e, consequentemente, de formação de uma nova família aos divorciados. O casamento é encarado no documento como base da organização familiar, sendo irrelevante a heterossexualidade, a homossexualidade, a bissexualidade, a transexualidade e a intersexualidade dos consortes: "Reservamos a todos, direitos iguais de matrimônio, respeitando a orientação sexual de cada um" (CARTA..., 2012, não paginado). Igualmente, a Carta Magna prescreve, frente à questão da adoção, iguais direitos entre "pais e mães heterossexuais, homossexuais, bissexuais, transexuais e intersexuais" (CARTA..., 2012, não paginado). A relação existente entre as chamadas minorias sociais aparece no depoimento do Babalorixá Magno Constantino a respeito da Carta Magna da Umbanda. O referido sacerdote traça balizas identitárias para a Umbanda como uma religião essencialmente próxima a essas minorias, o que demandaria um posicionamento claro da religião frente às questões da minoria:

As religiões de matriz africana e nós umbandistas somos os que mais sofremos, somos a todo tempo marginalizados por religiões cristãs (mais especificamente evangélicos), haja vista que nosso culto compõe fiéis das ditas minorias: Negros, Indígenas, Africanos, Lésbicas, Gays, Bissexuais, Travestis, Transexuais, Transgêneros, mães solteiras, classe social de renda baixa, entre outros grupos. Abraçamos as minorias sim, pois não somos proselitistas, todos somos Divinos e sagrados (SOUZA, 2017, p. 47).

O posicionamento de Magno Constantino é sumamente indiciário das trans- 
formações apresentadas pelo discurso dos intelectuais e dirigentes da Umbanda na atualidade. Em um momento no qual a sociedade brasileira apresenta relevantes transformações na direção de identidades até recentemente sem visibilidade sociopolítica, este sacerdote umbandista manifesta um projeto includente para a religião. Com esse posicionamento, Constantino traça uma linha diferencial frente às denominações que ou não reconhecem, ou não apoiam, ou não explicitam um posicionamento frente a essas questões.

Figura 1 - O engajamento de gênero na Carta Magna da Umbanda e a presença do arco-íris na composição gráfica

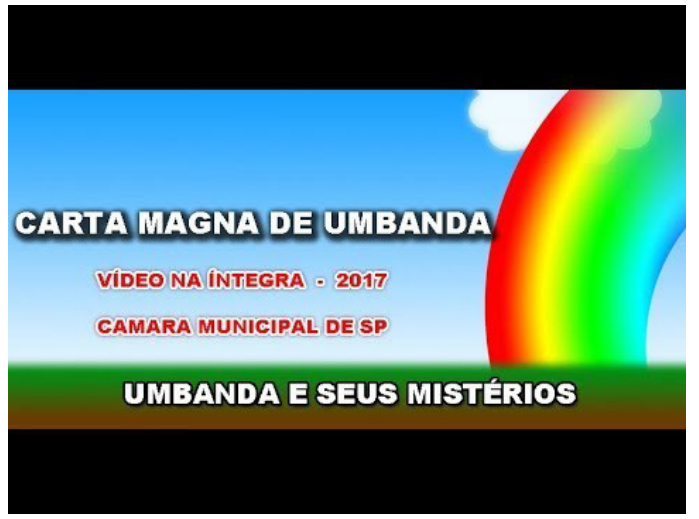

Fonte: <https://www.google.com.br/search?q=carta+magna+d a+umbanda\&source $=$ Inms\&tbm $=$ isch \&sa $=X \&$ ved $=0$ ah UKEwjEycDOsJ3cAhWLr1kKHUd0Bp8Q_AUICigB\&bi $w=1920 \& b i h=974 \#$ imgrc $=$ GR9ulHIWKAssIM $>$. Acesso em: 20 abr. 2018.

O teor do posicionamento de Magno Constantino é referendado no projeto visual do banner de chamada do vídeo de lançamento da Carta Magna da Umbanda na Câmara Municipal de São Paulo, em 2017 (Figura 1). A presença do arco-íris, um conhecido identificador do gay rights movement, pode ser indiciário das tentativas de representatividade e diálogo com o movimento por parte dos organizadores do documento.

Igualmente, a Carta Magna da Umbanda quis tornar claro o posicionamento da religião frente às questões que gravitam em torno dos fundamentos religiosos da vida. Sendo assim, posicionou-se frente ao aborto, à eutanásia e à pena de morte. Frente a todos esses assuntos, o posicionamento da Carta Magna da Umbanda é contrário, por enxergá-los como atentados contra o direito à vida, pois "só o criador, através da Sua, Onisciência, Onipresença, e Onipotência, sabe o momento do desenlace carnal de qualquer indivíduo" (CARTA..., 2012, não paginado). Em relação ao direito à vida do nascituro, o documento considera-o inviolável desde o momento da sua concepção. $\mathrm{O}$ controle da natalidade é incentivado como uma questão de foro íntimo, incluindo a escolha dos meios contraceptivos, vistos "como um modo de proteger a vida" (Carta..., 2012, não paginado). Ainda em relação aos contraceptivos, o documento diretamente cita o uso de preservativos. Esses não são vistos meramente como contraceptivos, mas como formas de evitar doenças sexualmente transmissíveis. Com isso, o documento claramente adota um posicionamento voltado para uma leitura positiva do prazer sexual, não o subordinando à procriação, conforme aparece no ocidente, desde o período clássico, com Aristóteles (ZILLES, 2009). Na esteira da biologia aristotélica, os teólogos cristãos partiram para a condenação dos atos considerados contrários à natureza (não praticados com o fim de procriação) e para a aceitação daqueles considerados segundo a natureza (praticados com o fim de procria- 
ção) (ZILLES, 2009). Nesse sentido, assevera o documento:

A Umbanda apoia o uso de preservativos e métodos contraceptivos, como meios de proteção contra DST (doenças sexualmente transmissíveis) e prevenção de gravidez indesejada. Cada qual deve saber e escolher o momento de gerar um novo ser, que necessitará de amor, compreensão, educação, orientação e discernimento ao longo de sua vida. Nesse sentido, o uso de métodos contraceptivos é um meio de proteger a vida (CARTA..., 2012, não paginado).

A Carta Magna da Umbanda parece ir ao encontro das características apontadas por Natividade e Oliveira (2007) no campo religioso afro-brasileiro, no sentido de uma maior flexibilização da moral sexual. As explícitas menções do documento em relação à aceitação de novos modelos familiares, bem como dos comportamentos homossexual, transexual, bissexual e intersexual, acenam nessa direção. Especificamente sobre o tema da presença homossexual nas religiões afro-brasileiras, existe uma literatura já bem considerável, desde o trabalho pioneiro de Ruth Landes (1967). Neste sentido, Monique Augras, estudando as regras, preceitos e interdições no campo afro-brasileiro, defende que, mais do que um sistema fechado de enunciações, há que se atender às modulações cotidianas da vontade dos Orixás: "Vale dizer, o que importa não é a cega obediência aos preceitos, o fundamental é atender à vontade dos deuses" (AUGRAS, 2011, p. 175). Essa flexibilização comportamental existente na Carta Magna da Umbanda seria impensável em um documento como os Anais do Primeiro Congresso Brasileiro do Espiritismo de Umbanda, completamente refratário ao passado africano e totalmente voltado para o atendimento aos códigos simbólicos e objetivos vigentes na primeira metade do século XX (ISAIA, 2009). Aliado a esses posicionamentos, o documento considera a laicidade do estado o princípio fundamental para o atendimento das demandas de uma sociedade plural. A flexibilização comportamental defendida na Carta Magna da Umbanda compõe-se com as características includentes e voltadas para o passado e a identidade africanos da Umbanda na atualidade. Saber contentar os Orixás compõe-se na Umbanda com a matriz judaico-cristã.

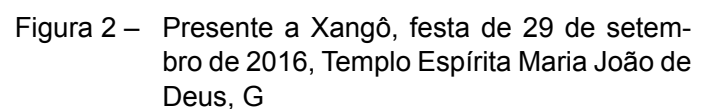

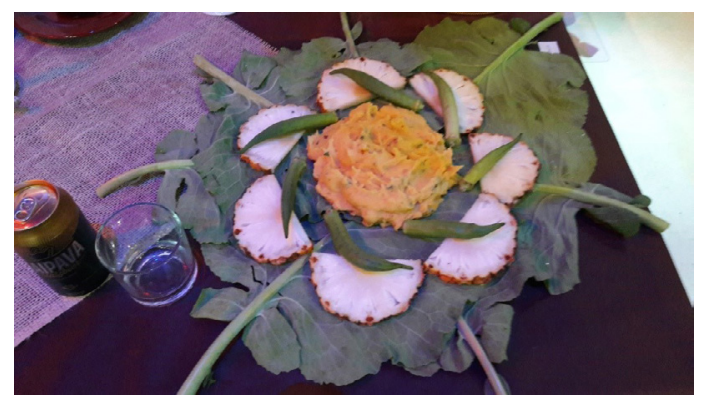

Fonte: acervo do autor.

\section{Direitos humanos e ecologia na Carta Magna da Umbanda}

Outra questão importante, relacionada aos direitos humanos e às regras de convivência social, aparece na Carta Magna, ao referir-se à característica ecológica da Umbanda. Nesse sentido, o documento, no seu preâmbulo, mostra a Umbanda como uma religião "cristã, natural e ecológica" (CARTA..., 2012, não paginado). Não apenas encara a defesa do meio ambiente como prio- 
ridade, tendo em vista que a terra é a casa comum de todos, como também explicita a ligação estreita que deve existir entre o culto aos Orixás, aos ancestrais e à natureza:

Explicando que a Umbanda como religião Cristã, Natural e Ecológica, têm em seus seguidores os defensores da Natureza; entendemos que os Sagrados Orixás se manifestam magneticamente com mais intensidade nos sítios vibratórios da natureza, aonde os religiosos de Umbanda vão constantemente, promovendo concentrações para refazimento energético, harmonizações e captação de energias sublimes, reequilibrando-os com as forças da Mãe Natureza (CARTA..., 2012, não paginado).

Fica clara na leitura do documento a sua relação com a perspectiva holista e globalista capitaneada pela ONU (IANNI, 2001; HENDERSON, 2003), no sentido de pensar uma comunidade mundial, regida, entre outros critérios, pelas exigências de uma harmonia entre homem e meio ambiente; projeto estreitamente ligado ao de uma reformulação religiosa, com o fim dos particularismos de crença.

Figura 3 - A construção de uma identidade religiosa comprometida tanto com a tradição afrodescendente quanto com a defesa do meio ambiente, assumida na Carta Magna

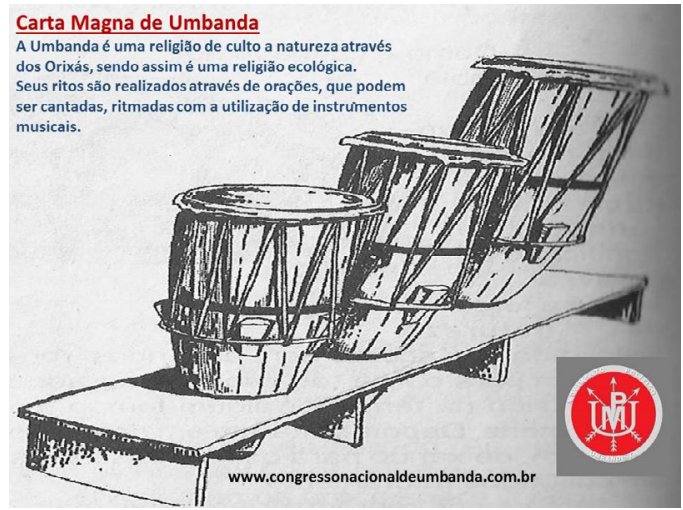

Fonte: Movimento Político Umbandista (2014, não paginado).
Ainda sobre a ligação entre a defesa do meio ambiente e as características intrínsecas à Umbanda, com a prescrição de "trabalhos" em matas, cachoeiras, mares, rios, entre outros recursos naturais, o documento prescreve a necessidade do uso de materiais biodegradáveis.

A religião de UMBANDA defende a Natureza, preza pelas matas, mares, rios, cachoeiras e nascentes. Preza também pela fauna e flora, contribuindo, assim, com os Tratados Internacionais de preservação da Natureza, indicando a necessidade de meios de desenvolvimento que não a agridem (CARTA..., 2012, não paginado).

Dessa forma, o documento não apenas aprofunda sua defesa da ecologia, como também adentra em uma questão extremamente atual, relacionando política de direitos humanos e direito ao ambiente. Essa ligação é outro ponto comum entre a Carta Magna da Umbanda e documentos exarados pela ONU, como, por exemplo, a Declaração de Estocolmo de 1972 (DECLARATION, 1972). Neste documento, explicita-se a defesa da vida em um planeta sadio como um direito humano fundamental, passível de ações concretas por parte dos estados membros, articulando-se com a Agenda 21, assinada no Rio de Janeiro, em 1992 (CONFERÊNCIA..., 1995).

Portanto, a Carta Magna da Umbanda insere-se mais ainda em uma agenda atual, ao posicionar-se frente a questões de sustentabilidade e de relações com os direitos humanos. Aliás, direitos humanos e direito ao desfrute de um meio ambiente equilibrado apresentam interligação, já que ambos têm um objetivo comum, que é a qualida- 
de de vida de todos os habitantes da terra (HAMMARSTRÖN; CENCI, 2012).

\section{Concluindo}

A Carta Magna da Umbanda, vista como uma fonte histórica, traz algumas informações explícitas ou indiciárias extremamente importantes para o historiador. Analisando o seu caráter "monumental", é possível chegar a peculiaridades não existentes em outros documentos exarados de líderes umbandistas no passado, a começar pelo público-alvo a que se destina e aos assuntos elencados como prioritários no posicionamento daqueles que têm o projeto de falar em nome da Umbanda brasileira. Ao contrário de outros documentos, a fonte em questão destina-se a um público maior que os seguidores da religião umbandista, voltando-se também para os não religiosos e dirigindo-se prioritariamente aos estudantes e intelectuais ligados às ciências humanas. Estes aparecem no documento, inclusive, precedendo os adeptos da Umbanda, como público-alvo a ser atingido. Igualmente, o documento tenta clarear o posicionamento umbandista frente a questões extremamente atuais que, não raro, são motivo de discussões doutrinárias nas denominações religiosas da atualidade. $\mathrm{O}$ explícito posicionamento frente a questões como identidades de gênero, contracepção, aborto e novos modelos familiares é indiciário de uma tentativa dos líderes umbandistas de dar uma resposta a questões extremamente atuais. Por certo, devido às características da Umbanda, o posicionamento do documento frente a questões tão candentes e polêmi- cas não pode ser visto como definitivo. A multiplicidade empírica e a atomização do exercício da autoridade reveladas pela Umbanda no Brasil traem completamente a possibilidade de pensar-se o documento como realidade canônica. Contudo, o tratamento e a centralidade dados à questão dos direitos humanos na Carta Magna evidenciam o projeto propositivo do grupo que o redigiu, procurando construir discursivamente uma Umbanda atualizada e sintonizada com a pluralidade e a complexidade do mundo contemporâneo.

\section{Abstract}

This text addresses a current document, which represents the positioning of some Umbanda leaders. The central issue addressed in this is the one related to human rights, seeking to link Umbanda with current and articulated guidelines with micro and macro social organization in the country and in the world. In this sense, it is positioned, among others, in the face of issues involving citizenship, gender, ecology and reproductive policy.

Keywords: Human rights. Medium related religions. Umbanda.

\section{Resumen}

Este texto aborda un documento actual, representativo del posicionamiento de algunos líderes de la Umbanda. La cuestión central tratada en el mismo es la relativa a los derechos humanos, buscando articular la Umbanda con pautas 
actuales y articuladas con la organización micro y macro social en el país y en el mundo. En este sentido se sitúa, entre otras, frente a cuestiones que involucran la ciudadanía, el género, la ecología y la política reproductiva.

Palabras clave: Derechos humanos. Religiones mediúnicas. Umbanda.

\section{Nota}

1 Disponível em: <https://www.google.com.br/ search $? q=$ carta + magna $+d a+$ umbanda\&sour $c e=1 n m s \& t b m=i s c h \& s a=X \& v e d=0 a h U K E w-$ jEycDOsJ3cAhWLr1kKHUd0Bp8Q_AUICigB\&biw $=1920 \&$ bih $=974 \#$ imgrc $=$ GR9ulHIWKAsslM:>. Acesso em: 20 abr. 2018.

\section{Referências}

CONFERÊNCIA DAS NAÇÕES UNIDAS SOBRE O MEIO AMBIENTE E O DESENVOLVIMENTO. Agenda 21. Brasília: Câmara dos Deputados, 1995.

AUGRAS, Monique. Quizilas e preceitos. Transgressões, reparação e organização dinâmica do mundo. In: MOURA, Carlos Eugênio Marcondes de. Culto aos Orixás. Voduns e Ancestrais nas Religiões Afro-Brasileiras. Rio de Janeiro: Pallas, 2011. p. 78-102.

BOURDIEU, Pierre. A economia das trocas simbólicas. São Paulo: Perspectiva, 2001.

BIRMAN, Patrícia. Registrado em Cartório, com firma reconhecida: a mediação política das federações da umbanda. In: Brown, Diana et al. Umbanda e Política. Rio de Janeiro: Marco Zero, 1985. p. 80-121.

BROWN, Diana. Uma história da Umbanda no Rio. In: Brown, Diana et al. Umbanda e Política. Rio de Janeiro: Marco Zero, 1985. p. 9-42.
CÂMARA MUNICIPAL DE LIMEIRA. 2013. Disponível em: <http://limeira.sp.leg.br/historia/galeriaVereadores.php?leg=59>. Acesso em: 25 nov. 2017.

CARTA MAGNA DA UMBANDA (s.n.t). 2012. (Arquivo pessoal de Marne Franco Rosa).

DECLARATION OF THE UNITED NATIONS CONFERENCE ON THE HUMAN ENVIRONMENT. 1972. Disponível em: <https:// mwvlw.rlp.de/fileadmin/mwkel/ Abteilung_2/8206/06_Nachhaltigkeit_global/1972_Stockholm_Erklaerung_en.pdf > . Acesso em: 30 mar. 2018.

DOCUMENTO OFICIAL PARA A RELIGIÃO DE UMBANDA CARTA MAGNA INTERNACIONAL DA UMBANDA (s.n.t). 2012. (Arquivo pessoal de Marne Franco Rosa).

CONCONE, Maria Helena Villas Boas; NEGRÃO, Lísias Nogueira. Umbanda: da repressão à cooptação. In: Brown, Diana et al. Umbanda e Política. Rio de Janeiro: Marco Zero, 1985. p. 43-79.

HAMMARSTRÖN, Fátima; CENCI, Daniel Rubens. Direitos Humanos e meio ambiente: a educação ambiental como forma de fortalecer a interrelação. Revista Eletrônica em Gestão, Educação e Tecnologia Ambiental REGET/UFSM, Santa Maria, v. 5, n. 5, p. 825-834, 2012.

HENDERSON, Hazel. Além da Globalização. Modelando uma economia sustentável. São Paulo: Editora Pensamento-Cultrix, 2003.

HORTA, Juliana Souza. Do terreiro à tribuna: a atuação de Moab Caldas na Assembleia Legislativa do Rio Grande do Sul (1959-1969). Trabalho de Conclusão de Curso (Licenciatura em História) - Universidade Federal do Rio Grande do Sul, Porto Alegre, 2016.

IANNI, Otávio. Teorias da Globalização. Rio de Janeiro: Civilização Brasileira, 2001. 
ISAIA, Artur Cesar. Umbanda, intelectuais e nacionalismo no Brasil. Fênix. Revista de História e Estudos Culturais, Uberlândia, v. 9, n. 3, p. 1-22, 2012.

. Intolerância e preconceito na obra dos intelectuais da Umbanda. In: MANOEL, Ivan Aparecido; ANDRADE, Solange Ramos de. Tolerância e intolerância nas manifestações religiosas. Franca: UNESP, 2010. p. 71-87.

. O outro lado da repressão: a Umbanda em tempos de Estado Novo. In: . Crenças, sacralidades e religiosidades. Entre o consentido e o marginal. Florianópolis: Insular, 2009. p. 53-72.

KOSELLECK, Reinhart. O futuro passado. Contribuição à semântica dos tempos históricos. Rio de Janeiro: Editora PUC-Rio, 2006.

LANDES, Ruth. A cidade das mulheres. Rio de Janeiro: Civilização Brasileira, 1967.

MORAES, Gilvan Silveira. Moab Caldas: discursos que rompem silêncios na tribuna (19581966). Dissertação (Mestrado em História) - Programa de Pós-Graduação em História, Universidade Federal de Santa Maria, Santa Maria, 2017.

MOVIMENTO POLÍTICO UMBANDISTA. 2014. Disponível em: <http:/ / movimentopoliticoumbandista.blogspot.com.br/> Acesso: 20 maio 2016.

NATIVIDADE, Marcelo; OLIVEIRA, Leandro de. Religião e intolerância à homossexualidade. Tendências contemporâneas no Brasil. In: SILVA, Wagner Gonçalves da. Intolerância Religiosa. Impactos do neopentecostalismo no campo religioso afro-brasileiro. São Paulo: Editora da USP, 2007. p. 121-161.

PRANDI, Reginaldo. Segredos guardados. Orixás na alma brasileira. São Paulo: Companhia das Letras, 2005.

ROSA, Marme Franco. Entrevista. Balneário Camboriú, 30 maio 2016. (Arquivo do Autor).
SILVA, Wagner Gonçalves da. Religião e identidade cultural negra: católicos, afrobrasileiros e neopentecostais. Cadernos de Campo, São Paulo, n. 20, p. 295-303, 2011.

SOUZA, Ortiz Belo de et al. Carta Magna da Umbanda. 2017. Disponível em: <http://www. cartamagnadaumbanda.com.br/wp-content/ uploads/2017/06/carta-completa.pdf > . Acesso em: 20 nov. 2017.

ZILLES, Urbano. Visão cristã da sexualidade humana. Teocomunicação, Porto Alegre, v. 39, n. 3, p. 336-350, 2009. 